\title{
INTERACTION OF METALLOPORPHYRINS WITH LIPID BILAYERS, A CALORIMETRIC STUDY
}

\author{
KATARZYNA PAMIN ${ }^{1}$, JAN POLTOWICZ ${ }^{1}$, JOANNA KIELKOWICZ ${ }^{2}$, ANDRZEJ. B. HENDRICH ${ }^{2,3}$ \\ ${ }^{1}$ Jerzy Haber Institute of Catalysis and Surface Chemistry, Polish Academy of Sciences, ul. Niezapominajek 8, 30-239 Kraków, Poland \\ ${ }^{2}$ Department of Biophysics, Wrocław Medical University, ul. Chałubińskiego 10, 50-368 Wrocław, Poland \\ ${ }^{3}$ Department of Medical Biology and Parasitology, Wrocław Medical University, ul. Mikulicza-Radeckiego 9, 50-367 Wrocław, Poland
}

Received January 26-th, 2011; accepted March 22, 2011; published online March 28, 2011

\begin{abstract}
The interaction of three metalloporphyrins, containing manganese, iron and cobalt atoms, with lipid bilayers composed of neutral (DPPC) or charged (DMPG) phospholipids were studied by means of scanning differential calorimetry. We found only minute effects exerted by studied compounds on DPPC, while phase transitions of charged DMPG were seriously affected by porphyrins. Analysis of experimental data revealed that due to the electrostatic interactions DMPG bilayers are perturbed not only in the polar head group region. Putative rearrangements of the polar heads packing affects also the acyl chain region of this lipid bilayer. Perturbation of DMPG polar heads induced by porphyrin in complex with manganese atoms is bigger than that induced by other porphyrins.
\end{abstract}

\section{INTRODUCTION}

Porphyrins, quite often in the form of complex with metal atoms, play crucial roles in many biological processes and applications, starting from the photosynthesis up to the photodynamic therapy (PDT) (Pandey et al., 2006). In this last case porphyrins are used as photosensitizing agents responsible for lightinduced damage of target cells or tissues. Most of the porphyrins used in PDT exert their photoactivity after association with the target structures - mainly biological membranes (Richelli, 1995). Binding with membranes and aggregation enhance porphyrin photoactivity and improve its efficiency (Richelli et al., 1998). Since singlet oxygen can diffuse on only a very short distance before its decay, it is very important to co-localize the photosensitizer molecules and target objects - lipids or membrane proteins (Brohnstein et al., 2004). Interactions with cellular membranes are also responsible for the increased uptake of the photosensitizer molecules by cancer cells (Hahn et al., 2006).

In present paper, using calorimetry, we investigated the interactions of three cationic metalloporphyrins with different types of lipids (charged or neutral). The chemical structure of studied porphyrins was identical and they differed exclusively in type of metal atom (Fe, $\mathrm{Co}, \mathrm{Mn})$ present in the center of porphyrin ring.

\section{MATERIALS AND METHODS}

Two synthetic lipids: 1,2-dipalmitoyl-sn-glycero-3phosphocholine (DPPC) and 1,2-dimyristoyl-sn-glycero3-phosphatidylglycerol (DMPG), both purchased from Sigma-Aldrich (Poznań, Poland) were used in microcalorimetric measurements without any further purification. Metalloporphyrins: $[\mathrm{Fe}\{\mathrm{T}(4-\mathrm{N}-$ $\mathrm{MePy}) \mathrm{P}\}] \mathrm{Cl}_{5}$, [Co $\left.\{\mathrm{T}(4-\mathrm{N}-\mathrm{MePy}) \mathrm{P}\}\right] \mathrm{Cl}_{5}$ and $[\mathrm{Mn}\{\mathrm{T}(4-$ $\mathrm{N}-\mathrm{MePy}) \mathrm{P}\} \mathrm{Cl}_{5}$ were purchased from Mid-Century Chemicals (Posen, IL, USA). Chemical structure of these compounds is presented in Fig. 1, hydrophilic character of these compounds was confirmed by their very good solubility in water.

Calorimetric samples were prepared by hydrating $2 \mathrm{mg}$ of lipid using $20 \mu \mathrm{l}$ of the solution of appropriate metalloporphyrin in $20 \mathrm{mM}$ Tris- $\mathrm{HCl}$ buffer $(150 \mathrm{mM}$ $\mathrm{NaCl}, 0.5 \mathrm{mM}$ EDTA, $\mathrm{pH}=7.4$ ) buffer. Concentration of metalloporphyrin in solution was chosen to obtain the desired porphyrin/lipid molar ratio. Samples were heated to the temperature $10{ }^{\circ} \mathrm{C}$ higher then the transition temperature of the used lipid and vigorously shaken until the homogeneous mixture was obtained. The mixtures were transferred to the aluminum pans and sealed. Samples were scanned immediately after preparation. Calorimetric measurements were performed using Rigaku calorimeter, which was partially rebuilt in our laboratory. For each porphyrin/lipid molar ratio two separate samples were prepared, each sample was scanned four times. Presented data are the average valu- 


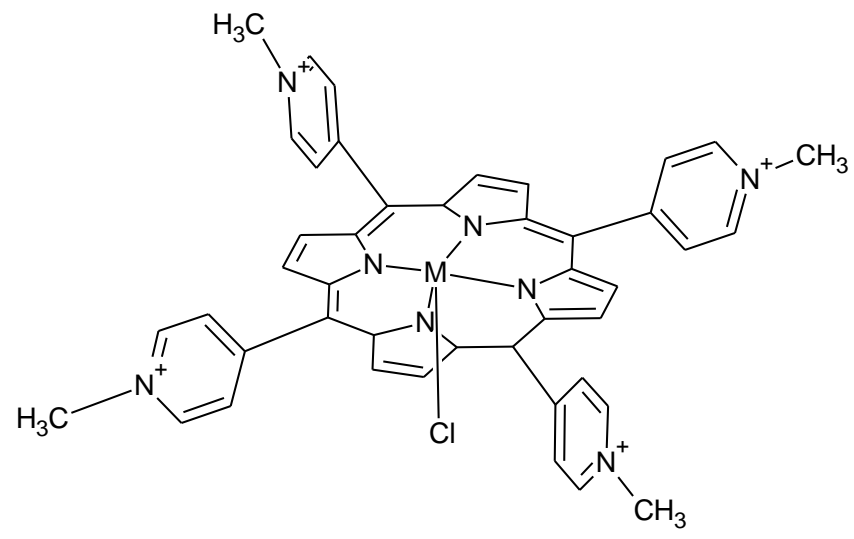

Fig. 1. Chemical structure of dissociated studied metalloporphyrins $(\mathrm{M}=\mathrm{Fe}, \mathrm{Co}, \mathrm{Mn})$.

es of eight measurements. The thermograms were stored on the computer hard disk and analyzed off-line using software developed in our laboratory, scanning rate was $1,25{ }^{\circ} \mathrm{C} / \mathrm{min}$. Pure water was used as the reference. Thermogram analysis allowed us to determine transition temperature $\left(\mathrm{T}_{\mathrm{m}}\right)$, enthalpy change during the transition $(\Delta \mathrm{H})$ and transition width at the transition peak halfheight $\left(\Delta \mathrm{T}_{1 / 2}\right)$.

\section{RESULTS AND DISCUSSION}

The effects of the metalloporhyrin presence in studied mixtures differed depending on the type of the lipid used in experiment. For DPPC we observed only minute changes in the thermal behavior of this lipid when it was mixed with any of the studied metalloporphyrins at
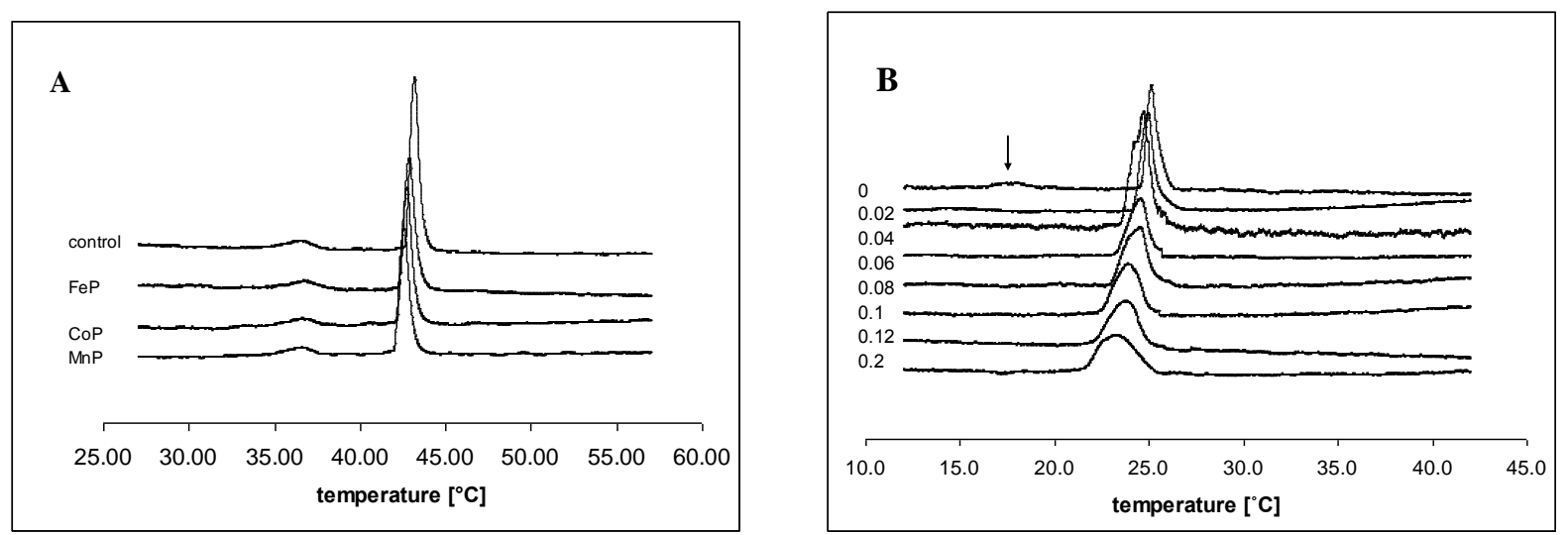

Fig. 2. Example thermograms of: A - DPPC mixed with three studied metalloporphyrins at 0,2 porphyrin/lipid molar ratio, B - DMPG mixed with $[\mathrm{Mn}\{\mathrm{T}(4-\mathrm{N}-\mathrm{MePy}) \mathrm{P}\}] \mathrm{Cl}_{5}$ at different porhyrin/lipid molar ratios. The top thermogram represents pure lipid. An arrow in panel B points to the DMPG's pretransition (poorly visible due to the scale of figure).

porphyrin/lipid molar ratio 0,2. First of all the DPPC's pretransition was not significantly affected by metalloporphyrins. Due to the broadness of transition peaks precise determination of transition temperature was not possible but slight increase of this parameter in the presence of porphyrins could be seen in Fig. 2A. This transition is sensitive to any bilayer packing perturbations (Heimburg, 2000) and therefore its presence in lipid/porphyrin mixtures can be treated as an indicator for the absence of any important lipid molecule's packing alterations. Possible increase of pretransition temperature could point to the localization of porphyrins in the polar head region of DPPC bilayers. As can be seen in Fig. 2A metalloporhyrins caused slight decrease of the DPPC's main transition temperature $\quad\left([\mathrm{Fe}\{\mathrm{T}(4-\mathrm{N}-\mathrm{MePy}) \mathrm{P}\}] \mathrm{Cl}_{5}-0,17^{\circ} \mathrm{C}\right.$, $[\mathrm{Co}\{\mathrm{T}(4-\mathrm{N}-\mathrm{MePy}) \mathrm{P}\}] \mathrm{Cl}_{5}-0,39^{\circ} \mathrm{C}$ and $[\mathrm{Mn}\{\mathrm{T}(4-\mathrm{N}-$ MePy)P $\}] \mathrm{Cl}_{5}-0,57^{\circ} \mathrm{C}$ ) but enthalpy and transition peaks width were not affected. According to Przyczyna et al. (2002) this small decrease of main transition 

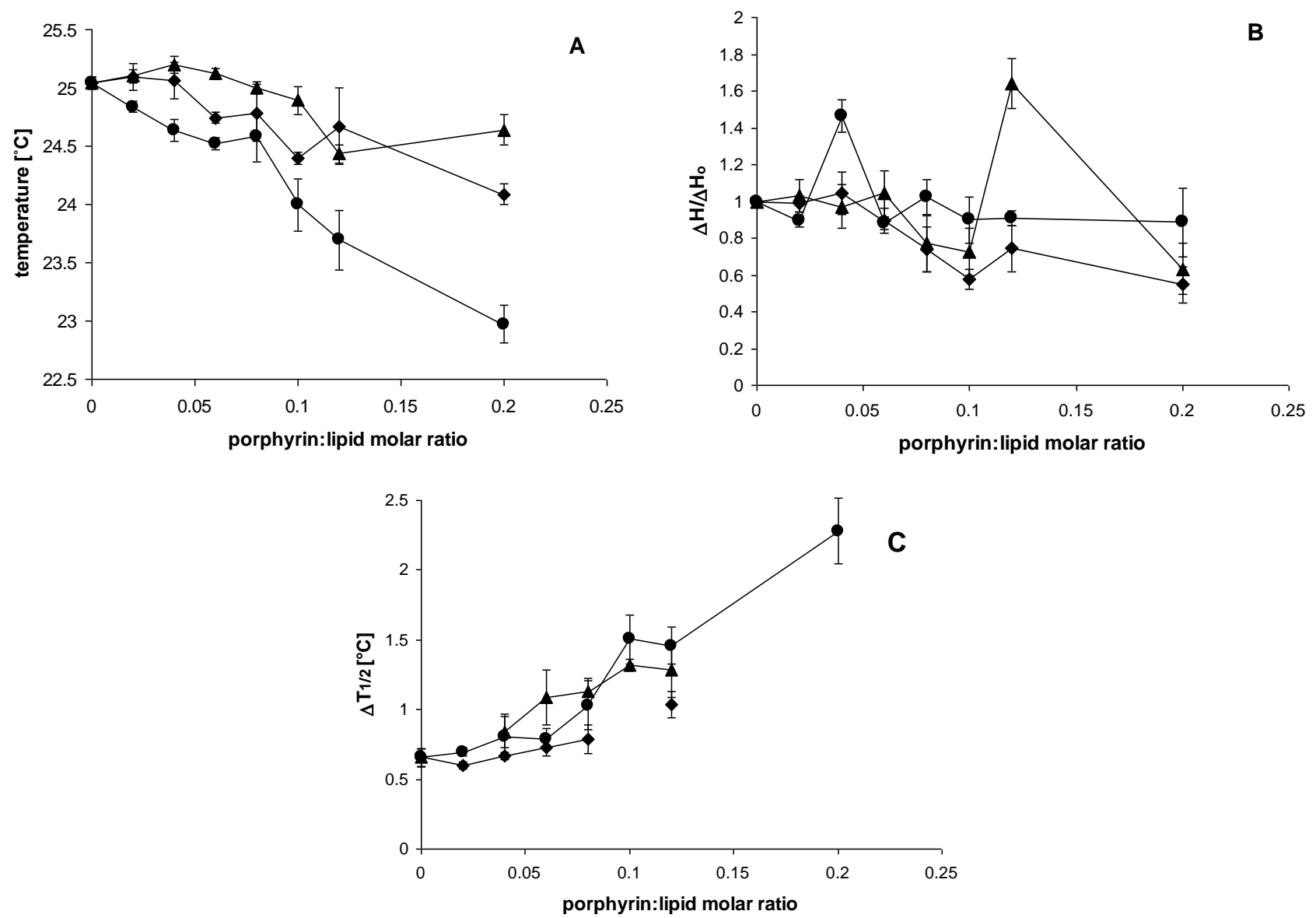

Fig. 3. Alteration of DMPG main phase transition parameters induced by the presence of metalloporphyrins: $-[\mathrm{Mn}\{\mathrm{T}(4-\mathrm{N}-\mathrm{MePy}) \mathrm{P}\}] \mathrm{Cl}$, - $-[\mathrm{Co}\{\mathrm{T}(4-\mathrm{N}-\mathrm{MePy}) \mathrm{P}\}] \mathrm{Cl}_{5}, \boldsymbol{\Delta}-[\mathrm{Fe}\{\mathrm{T}(4-\mathrm{N}-\mathrm{MePy}) \mathrm{P}\}] \mathrm{Cl}_{5}$. A - transition temperature, $\mathrm{B}$ - relative transition enthalpy, $\mathrm{C}-$ transition width at peak half-height. Determination of $\Delta \mathrm{T}_{1 / 2}$ for porphyrin:lipid molar ratio 0,1 of $[\mathrm{Co}\{\mathrm{T}(4-\mathrm{N}-\mathrm{MePy}) \mathrm{P}\}] \mathrm{Cl}_{5}$ as well as for 0,2 of $[\mathrm{Co}\{\mathrm{T}(4-\mathrm{N}-\mathrm{MePy}) \mathrm{P}\}] \mathrm{Cl}_{5}$ and $[\mathrm{Fe}\{\mathrm{T}(4-\mathrm{N}-\mathrm{MePy}) \mathrm{P}\}] \mathrm{Cl}_{5}$ was not possible due to the bad shapes of thermograms.

temperature could be rather related to the bilayer hydration changes induced by the presence of dissociated $\mathrm{Cl}^{-}$ions than to the interactions between positive charges carried by porphyrin molecules and lipid headgroups. Cations usually affect the transition temperature to much bigger extent and they increase themain transition temperature of DPPC (Koynova \& Caffrey, 1998).

Contrary to neutral DPPC the thermal behavior of negatively charged DMPG was significantly perturbed by the presence of metalloporphyrins (see the example themograms in Fig. 2B). As can be seen in this figure the DMPG's pretransition was abolished by the lowest of tested in experiments [Mn $\{\mathrm{T}(4-\mathrm{N}-\mathrm{MePy}) \mathrm{P}\}] \mathrm{Cl}_{5} / \mathrm{lipid}$ molar ratios $(0,02)$. The same result was recorded also for other two studied metalloporphyrins. The effects exerted by porphyrins on the parameters of DMPG main phase transition are presented in Fig. 3. The temperature of DMPG main transition was remarkably decreased in a concentration-dependent manner by all studied compounds. The effects of $\mathrm{Co}^{-}$and $\mathrm{Fe}$ substituted porphyrins were less pronounced than that of Mn-substituted one, which at the highest of studied molar ratios to lipid $(0,2)$ decreased $\mathrm{T}_{\mathrm{m}}$ by almost $2{ }^{\circ} \mathrm{C}$ (Fig. 3A). The concentration-dependent increase of DMPG's transition width was observed also for all studied compounds. Despite that determination of $\Delta T_{1 / 2}$ was not possible for the highest molar ratios of $\mathrm{Co}$ - and Fe-substituted porphyrins, analyzing Fig. 3C one can conclude that $[\mathrm{Mn}\{\mathrm{T}(4-\mathrm{N}-\mathrm{MePy}) \mathrm{P}\}] \mathrm{Cl}_{5}$ broadened the transition peaks most effectively. Also the enthalpy of main transition was affected by the presence of metalloporphyrins in studied mixtures. Neglecting two points shown in Fig. 3B (molar ratios 0,04 for Mn- 
substituted and 1,2 for Fe-substituted porphyrins), which might be the result of cumulating experimental errors, the gradual decrease of $\Delta \mathrm{H}$ can be seen in this figure. Opposite to $\mathrm{T}_{\mathrm{m}}$ and $\Delta \mathrm{T}_{1 / 2}$ the transition enthalpy was less significantly decreased by $[\mathrm{Mn}\{\mathrm{T}(4-\mathrm{N}-\mathrm{MePy}) \mathrm{P}\}] \mathrm{Cl}_{5}$. In our opinion the described above effects can be attributed to the electrostatic attraction between the positive charges carried by metalloporphyrins and negative charges of DMPG polar head groups. Due to their charges porphyrin molecules can not penetrate the hydrophobic core of bilayer and they stay close to the polar region. Such localization was postulated by Richelli et al. $(1990,1991)$ in the study on the interactions of hematoporphyrin and DPPC liposomes. Similar conclusions were drawn also by Rich et al. (1992) for hematoporhyrin derivativephosphatidylcholine systems (monolayer and bilayer) at neutral $\mathrm{pH}$. pH-dependent depth of membrane penetration by hematoporphyrins was also reported by Bronshtein et al., (2005). The rigid structure of porphyrin ring presumably forces lipid head groups to adopt the spatial arrangement in which they fit to the distribution of charges in porphyrins. Alteration of lipid head groups packing affects also the hydrophobic region and weakens the interactions between lipid molecules. In calorimetric measurements such perturbation is observed as decrease of main phase transition temperature and transition enthalpy accompanied by the peak broadening (decrease of transition's cooperativity). Membrane perturbation induced by different porphyrins was observed in several laboratories. For example glycosilated tetraphenyl-porphyrins, depending on their structure, can penetrate lipid bilayer to the different depth and induce loosening of membrane structure (Voszka et al., 2007). The strong membrane destabilization induced by small amounts of chlorophyll a was recently found by Vladkova et al., (2010).

The type of metal present in complex with porphyrin molecule seems to possess also some importance. Presence of manganese seems to affect to greater extent the main phase transition parameters related with the properties of polar bilayer region $\left(\mathrm{T}_{\mathrm{m}}\right.$ and $\left.\Delta \mathrm{T}_{1 / 2}\right)$ (Jain \& $\mathrm{Wu}, 1977)$. Relatively smaller changes induced by this metal in transition enthalpy might suggest that lipid acyl chains are not profoundly affected. Iron and cobalt present in complexes perturb polar region of lipid bilayer less effectively but their impact on acyl chains seems to somehow bigger than that of Mn.

Summarizing the presented above results we can conclude that interactions between charged metalloporphyrins and lipids are governed by the electric nature of involved molecules. Neutral, not charged lipids are not affected by the presence of porphyrins. Contrary the charged lipids attract metalloporphyrin molecules and as a result of interaction the polar as well as hydrophobic parts of lipid bilayer are perturbed. The type of metal atom present in complex with porphyrin molecule is also important.

\section{REFERENCES}

Bronshtein I., Afri M., Weitman H., Frimer A.A., Smith K.M., Ehrenberg B. (2004) Porphyrin depth in lipid bilayers as determined by iodide and parallax fluorescence quenching methods and its effect on photosensitizing efficiency, Biophys. J. 87, 1155-1164.

Bronshtein I., Smith K.M., Ehrenberg B. (2005) The effect of $\mathrm{pH}$ on the topography of porphyrins in lipid membranes. Photochem. Photobiol. 81, 446-451.

Hahn SM, Putt ME, Metz J, Shin DB, Rickter E, Menon C, Smith D, Glatstein E, Fraker DL, Busch TM. (2006) Photofrin uptake in the tumor and normal tissues of patients receiving intraperitoneal photodynamic therapy, Clin. Cancer. Res. 7, 704-708.

Heimburg T. (2000) A model for the lipid pretransition: coulping of ripple formation with the chain-melting transition, Biophys. J. 78, 1154-1165.

Jain M.K. \& Wu N.M. (1977) Effects of small molecules on the dipalmitoyl lecithin liposomal bilayer. III. Phase transitions of lipid bilayers. J. Membrane Biol. 34, 157-201.

Koynova R. \& Caffrey M. (1998) Phases and phase transitions of the phosphatidylcholines, Biochim. Biophys. Acta 1376, 91-145.

Pandey R.K., Goswami L.N., Chen Y., Gryshuk A., Missert J.R., Oseroff A., Dougherty T.J. (2006) Nature: a rich source for developing multifunctional agents. Tumor-imaging and photodynamic therapy, Lasers. Surg. Med. 38, 445-467.

Przyczyna A., Różycka-Roszk B., Langner M. (2002) The effect of selected anions on dipalmitoylphosphatidylcholine phase transitions, Z. Naturforsch. 57C, 712-716.

Richelli F., Jori G., Moreno G., Vinzens F., Salet C. (1990) Factors influencing the distribution pattern of porphyrins in cell membranes, J. Photochem. Photobiol. 6, 69-77.

Richelli F., Jori G., Gobbo S., Tronchin M. (1991) Liposomes as models to study the distribution of porphyrins in cell membranes. Biochim. Biophys. Acta 1065, 42-48.

Ricchelli F. (1995) Photophysical properties of porphyrins in biological membrane, J. Photochem. Photobiol. B, 29, 109118.

Ricchelli F., Gobbo S., Moreno G., Salet C., Brancaleon L., Mazzini A. (1998) Photophysical properties of porphyrin planar aggregates in liposomes, Eur. J. Biochem. 253, 760765.

Rich M.R., Ferraro G., Brody S.S. (1992) Effects of pH on the binding of hematoporphyrin derivative to monolayer and bilayer membranes. Biochim. Biophys. Acta 1104, 269-272.

Vladkova R., Koynova R., Teuchner K., Tenchov B. (2010) Bilayer structural destabilization by low amounts of chlorophyll a. Biochim. Biophys. Acta 1798, 1586-1592.

Voszka I., Budai M., Szabo Z., Maillard P., Csik G., Grof P. (2007) Interaction of photosensitizers with liposomes containing unsaturated lipid. Chem. Phys. Lipids 145, 63-71. 